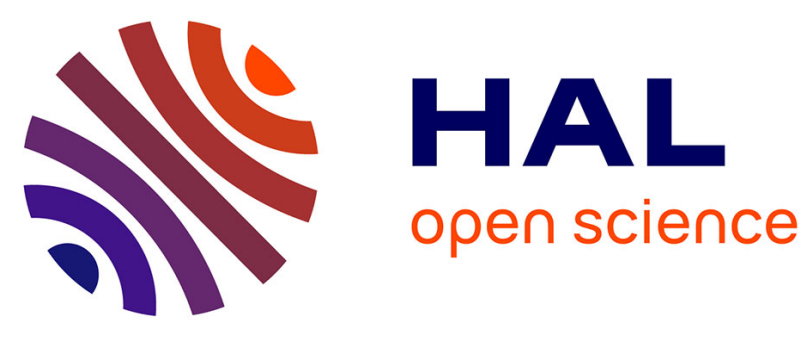

\title{
Fractionated gemtuzumab ozogamicin in association with high dose chemotherapy: a bridge to allogeneic stem cell transplantation in refractory and relapsed acute myeloid leukemia
}

Pierre-Edouard Debureaux, Myriam Labopin, Anne-Claire Mamez, Simona Lapusan, Françoise Isnard, Rosa Adaeva, Agnès Bonnin, Pierre Hirsch, François Delhommeau, Giorgia Battipaglia, et al.

\section{- To cite this version:}

Pierre-Edouard Debureaux, Myriam Labopin, Anne-Claire Mamez, Simona Lapusan, Françoise Isnard, et al.. Fractionated gemtuzumab ozogamicin in association with high dose chemotherapy: a bridge to allogeneic stem cell transplantation in refractory and relapsed acute myeloid leukemia. Bone Marrow Transplantation, 2020, 55 (2), pp.452-460. 10.1038/s41409-019-0690-2 . hal-02530730

\section{HAL Id: hal-02530730 \\ https://hal.sorbonne-universite.fr/hal-02530730}

Submitted on 3 Apr 2020

HAL is a multi-disciplinary open access archive for the deposit and dissemination of scientific research documents, whether they are published or not. The documents may come from teaching and research institutions in France or abroad, or from public or private research centers.
L'archive ouverte pluridisciplinaire HAL, est destinée au dépôt et à la diffusion de documents scientifiques de niveau recherche, publiés ou non, émanant des établissements d'enseignement et de recherche français ou étrangers, des laboratoires publics ou privés. 
Fractionated Gemtuzumab Ozogamicin in association with high dose Chemotherapy: a Bridge to Allogeneic stem cell Transplantation in Refractory and Relapsed Acute Myeloid Leukemia

Running Head: Gemtuzumab and chemotherapy in acute myeloid leukemia

Pierre-Edouard Debureaux ${ }^{1}$, Myriam Labopin ${ }^{1,2}$, Anne-Claire Mamez ${ }^{1}$, Simona Lapusan $^{1}$, Francoise Isnard $^{1}$, Rosa Adaeva ${ }^{1}$, Agnès Bonnin ${ }^{1}$, Pierre Hirsch ${ }^{2,3}$, Francois Delhommeau ${ }^{2,3}$, Giorgia Battipaglia $^{1}$, Remy Duléry ${ }^{1}$, Florent Malard ${ }^{1,2}$, Anne Vekhoff $^{1}$, Mohamad Mohty ${ }^{1,2}$, Ollivier Legrand $^{1,2^{*}}$, Eolia Brissot ${ }^{1,2^{*}}$

${ }^{1}$ Service d'Hématologie Clinique et de Thérapie cellulaire, Hôpital Saint Antoine, APHP, Paris, France; ${ }^{2}$ Sorbonne Université, Paris, France ${ }^{3}$ Service d'hématologie biologique, Hôpital Saint Antoine, APHP Paris, France

*OL and EB share senior authorship

Correspondance : Pierre-Edouard Debureaux

Service d'Hématologie Clinique et de Thérapie cellulaire,

Hôpital Saint Antoine, 75012 Paris France

Mail: pierre-edouard.debureaux@aphp.fr

Tel : +33149282624 


\begin{abstract}
:
Optimization of the salvage regimen is required to improve prognosis in primary refractory or relapsed acute myeloid leukemia (AML). In fit patients, a bridge to allogeneic transplant is the primary purpose of salvage. We tested the combination of fractionated gemtuzumab ozogamicin with cytarabine and mitoxantrone (MYLODAM schema) with primary endpoint of efficacy and safety. We also attempted to define predictive factors for survival and response after salvage.
\end{abstract}

We included 58 patients with a median age at salvage of 56 years. The overall response rate was $67 \%$. Leukemia-free survival (LFS) and overall survival (OS) at 2 years was 36\% (95\% CI: 23 - 49) and 54\% (95\% CI: 39 - 68), respectively. Treatment-related mortality was 7\%. Three veno-occlusive diseases (SOS/VOD) occurred during salvage. In the allogeneic group of 28 patients (48\%), LFS and OS at 2 years was $57 \%$ (95\% CI: 36.3 - 77.5) and $69 \%$ (95\% CI: 49.3 - 88.7), respectively. Incidences of non-relapse mortality, grade II-IV acute graft-versus-host disease (GVHD) and chronic GVHD were $16 \%, 40 \%$, and $45 \%$, respectively.

A GO-based intensive regimen is a viable option for salvage therapy and a feasible schedule as a bridge to allogeneic transplant.

\title{
Introduction
}

Despite the improvement in care, primary refractory or relapsed acute myeloid leukemia (PRAML) is associated with a dismal prognosis. Approximately one-third of patients younger than 60 years and $50 \%$ of older patients with newly diagnosed AML fail to achieve complete remission (CR) after first line intensive chemotherapy. ${ }^{1-3}$ Furthermore, nearly $40 \%$ of patients initially achieving first complete remission (CR1) experience relapse ${ }^{4}$, and the median duration of a second CR is often shorter than that of CR1. Refractory AML (20\% of patients) is a major unfavorable prognostic factor with a median survival of 12 months. ${ }^{5}$ Allogeneic hematopoietic stem cell transplantation (allo-HCT) is the only salvage option with curative potential in these two scenarios. ${ }^{6}$ However, disease status at transplant remains one of the 
main prognostic factors. ${ }^{7,8}$ There is no consensus on the optimum salvage therapy which may be used as a bridge to allo-HCT. ${ }^{9,10}$ Gemtuzumab ozogamicin (GO) is a humanized anti-CD33 antibody conjugated with the cytotoxic antitumor antibiotic calicheamicin. GO (6 or $9 \mathrm{mg} / \mathrm{m}^{2}$ during one day) first received accelerated approval in 2000 for treatment of CD33-positive AML in patients aged $\geq 60$ years of age who experienced disease relapse and were not considered candidates for cytotoxic chemotherapy. However, myelosuppression, fatal hepatotoxicity, and high risk of sinusoidal obstructive disease/veno-occlusive disease (SOS/VOD) were reported in the post-marketing setting. Finally, the confirmatory study, S02106, failed to demonstrate a clinical benefit for GO. ${ }^{11}$ A UK National Cancer Research Institute meta-analysis of 5 phase 3 trials of GO in adults studied 3.325 patients. ${ }^{12}$ This metaanalysis showed a statistically significant reduction in relapse rates and improved overall survival (OS) for GO-treated patients across these trials, without a significant increase in toxicity. The benefits appeared to be limited to patients with a favorable or intermediate-risk karyotype; patients treated on studies with $3 \mathrm{mg} / \mathrm{m}^{2}$ per dose or with a fractionated schedule of $3 \mathrm{mg} / \mathrm{m}^{2}$ on day 1,4 and 7 , experienced lower induction mortality. In light of this more favorable reassessment of randomized studies, GO was given full FDA approval in September 2017 for treatment of CD33-positive AML, both in the frontline and relapse setting. In the PR-AML setting, MIDAM protocol (GO $9 \mathrm{mg} / \mathrm{m}^{2}$ on day 4 , cytarabine $1 \mathrm{~g} / \mathrm{m}^{2}$ twice daily on day 1-5 and mitoxantrone $12 \mathrm{mg} / \mathrm{m}^{2}$ on day 1-3) has an overall response rate (defined as $\mathrm{CR}+\mathrm{CRi}$ (same as $\mathrm{CR}$ except for one criterion of peripheral blood count recovery) of $63 \% .^{13}$ In a phase 2 study of PR-AML, GO monotherapy demonstrated efficacy with an overall response rate $(\mathrm{CR}+\mathrm{CRi})$ of $33 \%$ and no grade $3-4$ liver toxicity. ${ }^{14}$ Based on the preceding results, we tested the combination of the fractionated $\mathrm{GO}\left(3 \mathrm{mg} / \mathrm{m}^{2}\right.$ on day 1,4 and 7$)$ with intensive chemotherapy, namely cytarabine $\left(1 \mathrm{~g} / \mathrm{m}^{2}\right.$ twice daily on day 1 - 
5) and mitoxantrone (12 mg/m² on day 1-3). This combination, namely MYLODAM, became a first salvage therapy for PR-AML at our center.

This single-center retrospective analysis aimed to assess the outcomes of PR-AML patients treated with this regimen.

\section{Patients and Methods}

\section{Patients}

This study included consecutive patients, potentially eligible for allo-HCT, treated in our institution that had either refractory or relapsed AML. Refractory AML was defined as failure to achieve a morphological CR in the bone marrow after one induction chemotherapy. Relapsed AML was defined by $>5 \%$ blast in the bone marrow after CR. The CD33 expression level was determined by dividing the mean fluorescence intensity of CD33 of the leukemic blast cells by the mean fluorescence intensity of the isotypic control. The threshold for positivity was defined as a ratio of $\geq 2$.

Detection of mutations FLT3-ITD, NPM1, and CEBPA was performed with standard routine techniques. $^{15}$

Cytogenetic analysis was performed on R-banding metaphases after 24-hour culture using standard procedures. Chromosomal rearrangements were confirmed by fluorescent in situ hybridization (FISH) analysis on 200 interphase nuclei. FISH was performed in CR samples (200-400 nuclei) to evaluate the clearance of chromosomal abnormalities with a theoretical detection threshold of $0.5 \%$.

Sequencing was performed using a 122 gene panel (HaloPlex Target Enrichment System®, Agilent Technologies) on a MiSeq® sequencer (IlluminaINC). Detailed protocols have been reported previously. ${ }^{16}$ After alignment, described variants were called using an Ensembl 
database. Non-described variants of potential interest were also sequenced using the Sanger method in the CD3+ fraction or the CR samples.

\section{Salvage regimen}

MYLODAM involved GO $3 \mathrm{mg} / \mathrm{m}^{2}$ (maximum dose $5 \mathrm{mg}$ ) on days 1, 4, and 7 with different chemotherapies. These mainly consisted of cytarabine $\left(1 \mathrm{~g} / \mathrm{m}^{2}\right.$ twice daily on day $\left.1-5\right)$ and an antracycline (either daunorubicin $60 \mathrm{mg} / \mathrm{m}^{2}$ or idarubicine $12 \mathrm{mg} / \mathrm{m}^{2}$ on day $1-3$ or mitoxantrone $12 \mathrm{mg} / \mathrm{m}^{2}$ on day 1-3). In the case of $\mathrm{CR}$, some patients received consolidation therapy with GO at $3 \mathrm{mg} / \mathrm{m}^{2}$ (maximum dose of $5 \mathrm{mg}$ ) on day 1 associated with chemotherapy (described in results). Patients who were fit for allo-HCT received an allogeneic graft if a donor was available after salvage or after consolidation.

\section{Response criteria}

Response to salvage therapy was evaluated by bone marrow studies which were performed earlier in the case of suspected disease progression. Complete remission (CR) was defined as normalization of blood and bone marrow: $\leq 5 \%$ of blasts, neutrophil count $>1.5 \mathrm{G} / \mathrm{L}$, and platelet count $>100 \mathrm{G} / \mathrm{L}$. CRi was defined as CR, except for one criterion of peripheral blood count recovery. CRMRD- was defined as CR with negative MRD by flow cytometry or molecular target. Overall response (OR) was defined as CR + CRi + CRMRD-. The European Leukemia Net (ELN) 2017 classification was used for prognostic classification and definition of response. $^{17}$

The WHO Toxicity Grading Scale was used to characterize toxicity. Evaluation of SOS/VOD was defined according to the grading system from the European Society for Blood and Marrow Transplantation. ${ }^{18}$

The primary endpoints in this analysis were the efficacy and safety profile of the MYLODAM salvage strategy. We also attempted to define predictive factors for survival and response after 
salvage. The following prognostic factors were recorded: age, cytogenetics, molecular data, blood cell counts, Sorror score ${ }^{19}$, and duration of CR1. We also recorded outcomes and safety data following allo-HCT.

\section{Statistical analysis}

Overall survival (OS) was calculated from the date of the start of therapy until death. LFS was calculated from the date of the start of therapy to disease recurrence or death.

Neutrophils recovery was determined as the interval from the therapy start to the first of 3 consecutive days with an absolute neutrophil above $0.5 \mathrm{G} / \mathrm{L}$. Platelets recovery was determined as the interval from therapy start to the first of 7 consecutive days with a platelet above $20 \mathrm{G} / \mathrm{L}$ without transfusion.

Acute GVHD (aGVHD) was graded according to Glucksberg classification ${ }^{20}$. Chronic GVHD (cGVHD) was diagnosed using the NIH classification ${ }^{21}$. Non-relapse mortality (NRM) was calculated from the date of HSCT to death not related to disease recurrence.

Cumulative incidence, treating non-event deaths as a competing risk, was used to estimate the probability of relapse, NRM, and acute and chronic GVHD. Kaplan - Meier curves were plotted for survival, and data for the various groups were compared using the log-rank test. Multivariate analysis was performed with a Cox model after the proportional hazards assumption was checked. Only significant univariate variables $(\mathrm{p}<0.1)$ were included. A pvalue of less than 0.05 was considered statistically significant. Statistical analyses were performed with SPSS 24.0 (SPSS Inc, Chicago, IL, USA) and R 3.4.1 (R Core Team (2017). R: A language and environment for statistical computing. R Foundation for Statistical Computing, Vienna, Austria. https://www.R-project.org/.) »

\section{Results}




\section{Patients' characteristics}

Fifty-eight patients (38 relapses and 20 primary refractory at chemotherapy) were included from 2009 to 2017 (Table 1). The median age at salvage was 56 years (range 16-74). Seventyfour percent were de novo AML $(n=43)$ and $26 \%$ secondary AML following myelodysplastic syndrome $(n=7)$ or therapy-related $(n=8)$. Eight patients $(16 \%)$ had a WHO classificationbased performance status (PS) >1 at salvage (missing data, $n=9$ ). Based on the ELN 2017 classification, the prognosis was favorable for 23 patients (40\%), intermediate for 21 patients (36\%) and adverse for 14 patients (24\%). Also, 46 patients (79\%) had minimal residual disease (MRD) target. All patients had CD33 positive AML (cut-off 20\%) with a median of $85 \%$ of expression (range $28-100 \%$ ). Bone marrow median blast count at the time of salvage treatment was $23 \%$ (range 0-94). Three molecular and 1 phenotypic relapse were treated.

Thirty-six (62\%) patients received fractionated GO with cytarabine $\left(1 \mathrm{~g} / \mathrm{m}^{2}\right.$ twice daily) and mitoxantrone $\left(12 \mathrm{mg} / \mathrm{m}^{2}\right.$ on day 1,2 and 3$)$. Fourteen patients $(24 \%)$ had fractionated GO combined with cytarabine ( $1 \mathrm{~g} / \mathrm{m}^{2}$ twice daily on day $\left.1-5\right)$ and daunorubicin $\left(60 \mathrm{mg} / \mathrm{m}^{2}\right.$ on day 1, 2 and 3). Seven patients (12\%) received fractionated GO combined with cytarabine $\left(1 \mathrm{~g} / \mathrm{m}^{2}\right.$ twice daily on day $1-5)$ and one (2\%) received fractionated GO combined with cytarabine (1 $\mathrm{g} / \mathrm{m}^{2}$ twice daily on day $\left.1-5\right)$ and idarubicin $\left(12 \mathrm{mg} / \mathrm{m}^{2}\right.$ on day 1,2 and 3$)$.

\section{Response}

The median follow-up period of alive patients was 26 months (range 2 - 84). The overall response rate was $67 \%(17 \% \mathrm{CRi}, 17 \% \mathrm{CR}$, and 33\% CRMRD-). After first cycle of MYLODAM, MRD negativity was achieved in $41 \%$ of patients with MRD target which included $8 \%$ with CRi and MRD-. Two predictive factors were associated with a lower response rate: refractory disease and male gender (Table 2). The median LFS and OS of all patients were 13.5 months (range 6-21) and 50 months (range 11-90), respectively (Figures 1 
and 2). LFS and OS at 2 years was 36\% (95\%CI 23-49) and 54\% (95\%CI $39-68)$,

respectively. Description of patients treatment and outcomes after MYLODAM was presented in figure 3. The overall response rate in patients with prior allo-HCT was $84 \%$ with 6 patients which could proceed to second allo-HCT. Five patients died in patients with prior allo-HCT. In relapse AML, longer duration of CR1 was associated with LFS ( $\mathrm{p}=0.03)$. In the multivariate analysis, LFS was significantly correlated with ELN prognostic score, with a lower LFS in the adverse risk group $(\mathrm{HR}=2.47$; 95\% CI: 1.05-5.79. $\mathrm{p}=0.038)$ and with differentiation mutation $(\mathrm{HR}=3.53,95 \% \mathrm{CI} 1.54-8.08 ; \mathrm{p}=0.003)$. At 2 years, relapse incidence (RI) was $62 \%$ and multivariate analysis demonstrated that both an adverse ELN score and differentiation mutations were associated with a higher RI (HR=2.67, 95\% CI: 1.17-6.38, $\mathrm{p}=0.027 ; \mathrm{HR}=3.61,95 \% \mathrm{CI}: 1.56-8.35, \mathrm{p}=0.003)$, respectively.

\section{Toxicity}

The median duration of hospitalization was 42 days (range, 22-133). Main toxicities are reported in Table 3. Cumulative incidences of neutrophils and platelets recovery at day 60 were $80 \%$ (95\%CI 67-89) and $91 \%$ (95\%CI 78-96), respectively. Three patients developed SOS/VOD without prophylaxis during the MYLODAM salvage therapy, 2 with moderate and 1 with very severe grade. Concerning infections, $57 \%$ were due to bacteriemia (13 enterobacteria, 10 Staphylococcus sp, 7 Enterococcus sp, 5 Pseudomonas sp, 4 Clostridium difficile, 1 Stenotrophomonas maltophila, and 1 Lactobacillus sp). Despite posaconazole prophylaxis in most patients, we observed 5 cases of aspergillosis (10\%) and 1 candidiasis (2\%). One pneumocystis occurred during salvage. Four patients required admission to ICU for sepsis $(n=2)$, hemorrhagic events $(n=1)$ and neurologic dysfunction $(n=1)$. Therapy-related mortality was 4 patients (7\%): 2 from infection, 1 from a hemorrhagic event, and 1 from very severe SOS/VOD. 


\section{Subsequent treatment}

Nineteen patients received consolidation treatment after CRi/CR/CRMRD. Protocols were $\mathrm{GO}$ at $3 \mathrm{mg} / \mathrm{m}^{2}$ on day 1 ( 8 patients); GO at $3 \mathrm{mg} / \mathrm{m}^{2}$ on day 1 associated with cytarabine 1 $\mathrm{g} / \mathrm{m}^{2}$ twice daily on day $1-4$ ( 8 patients); GO at $3 \mathrm{mg} / \mathrm{m}^{2}$ on day 1 associated with cytarabine 1 $\mathrm{g} / \mathrm{m}^{2}$ twice daily on day 1-4 and mitoxantrone at $12 \mathrm{mg} / \mathrm{m}^{2}$ on day $1-2$ (3 patients). Nine of these 19 also received a second consolidation. Protocols were GO at $3 \mathrm{mg} / \mathrm{m}^{2}$ on day 1 (3 patients); GO at $3 \mathrm{mg} / \mathrm{m}^{2}$ on day 1 associated with cytarabine $1 \mathrm{~g} / \mathrm{m}^{2}$ twice daily on day 1-4 (4 patients); GO at $3 \mathrm{mg} / \mathrm{m}^{2}$ on day 1 associated with cytarabine $1 \mathrm{~g} / \mathrm{m}^{2}$ twice daily on day $1-4$ and mitoxantrone at $12 \mathrm{mg} / \mathrm{m}^{2}$ on day 1-2 (2 patients). Three patients had an improvement in response with 2 patients in CR moving to CRMRD- and one patient in CRi moving to CR. Two patients experienced relapse during consolidation. No SOS/VOD occurred during consolidation courses. Two patients required ICU admission for sepsis.

In the non-allo-HCT group ( $\mathrm{n}=30), \mathrm{LFS}$ and OS at 2 years was $26 \%$ (range 14.7-50) and 33 $\%$ (range 22-61) respectively. Eighteen patients out of 30 experienced disease relapse that was treated with azacitidine $(n=7)$, cytarabine $(n=4)$, arsenic trioxide + All-Trans Retinoic Acid (ATRA) $(n=1)$ and best supportive care $(n=6)$. Refractory AML was the leading cause of death $(n=17)$.

\section{Allogeneic transplant group}

In all, $28(48 \%)$ patients could proceed to allo-HCT. The median time between treatment by MYLODAM and allo-HCT was 91 days (range 57-366 days). The main reason to exclude allo-HCT for the 30 other patients was that 19 were not fit enough after salvage treatment, 6 died before transplant, and for 5 patients no donor could be identified. The Sorror score for the transplant patients was calculated as 0 for 11 patients, 1 for 5 patients, 2 for 7 patients, and 
3 for 5 patients respectively. Stem cell sources were peripheral blood stem cells in 22 patients, bone marrow in 4 patients, and umbilical cord blood in 2 patients.

LFS and OS at 2 years was 57\% (range, 36.3-77.5) and 69\% (range, 49.3-88.7) respectively (Table 4). The cumulative incidences of grade II-IV acute GVHD and chronic GVHD were $40 \%$ and $46 \%$, respectively. At 2 years, the cumulative incidence of NRM was $16 \%$ (95\% CI: 8.5-33.3), and of RI was $25 \%$ (95\% CI: 10.5-46.8).

Despite the policy of our center to prevent SOS/VOD in this high-risk patient group by using defibrotide prophylaxis (21 out of 28 patients received prophylaxis), 5 cases of SOS/VOD occurred during allogenic transplant (3 moderate and 2 very severe). All 5 cases received TEC-RIC conditioning for allo-HCT in the 3 months after MYLODAM, defibrotide prophylaxis. However, no death related to SOS/VOD was observed.

Prophylactic donor lymphocyte infusions (DLIs) were administered to 4 patients. In the posttransplant setting, 5-azacitidine was administered to 8 patients: 4 patients in prophylaxis, 2 in preemptive treatment (MRD+), and 2 in relapse.

\section{Cytogenetics, molecular and Next Generation Sequencing (NGS) description}

Based on the classification of ELN 2017, 23 patients had a favorable prognosis, 21 had an intermediate prognostic, and 14 had an adverse prognostic. In terms of cytogenetics, 28 presented with a normal karyotype, 4 with monosomy 7, 3 with abnormalities in chromosome 3 , and 3 with $\mathrm{t}(\mathrm{v} ; 11 \mathrm{q} 23.3)$.

Forty-seven patients were able to have NGS analysis at diagnosis, and the profile of mutations is presented in Figure 4. The median number of mutations was 2 (range, 0-7), which did not have an impact on LFS and OS. We used a classification of mutations to determine prognosis with NPM1, FLT3 (FLT3-ITD, FLT3-TKD), CBF (inv(16), t(8;21)), methylation abnormalities (DNMT3A, TET2, IDH1, IDH2), signaling pathways (NRAS, KRAS, PTPN11, 
CBL, NF1, CS3FR), differentiation abnormalities (RUNX1, GATA 2, inv(3), t(3;3)), chromatin abnormalities (ASXL1, t(v;11q23.3), MLL, EZH2, ASXL2, BCOR), spliceosome (SF3B1, SRSF2, ZRSF2) and cohesin (SMC1A, STAG2, RAD21). Multivariate analysis showed that differentiation abnormalities were associated with a significantly lower LFS $(\mathrm{HR}=3.53,95 \% \mathrm{CI}: 1.54-8.08, \mathrm{p}=0.003)$ and a higher $\mathrm{RI}(\mathrm{HR}=3.61,95 \% \mathrm{CI}: 1.56-8.35$, $\mathrm{p}=0.003)$ (Table 2).

\section{Discussion}

This study shows that GO with chemotherapy in PR-AML is a very interesting salvage option for this high-risk group of patients. The overall response rate was achieved in $67 \%$ of patients, with OS and LFS rates of 54\% and 36\%, respectively. The safety profile was acceptable with $7 \%$ of TRM and $5 \%$ of SOS/VOD during salvage. Half of the patients could bridge to alloHCT, albeit with $32 \%$ of patients not enough fit to proceed and a an increased risk of SOS/VOD $(\mathrm{n}=5,18 \%)$ despite defibrotide prophylaxis.

These results seem to be superior or comparable to those observed with chemotherapy, GO as monotherapy, or GO plus chemotherapy. Indeed, studies using GO in combination with chemotherapy as a salvage regimen have shown a response rate of $38 \%-63 \% .^{14,22-24} \mathrm{With}$ the MIDAM protocol, Chevallier et al. evaluated 62 PR-AML patients, who received a combination of non-fractioned GO $\left(9 \mathrm{mg} / \mathrm{m}^{2}\right)$, cytarabine and mitoxantrone. ${ }^{22}$ The overall response rate was $63 \%(50 \% \mathrm{CR}$ and $13 \% \mathrm{CRi}$ ), and the 2-year OS and EFS were $41 \%$ and $33 \%$ respectively. Three percent of SOS/VOD was described with one death related to SOS/VOD. The combination of mitoxantrone and intermediate-dose cytarabine is known to be one of the most effective salvage regimens for PR refractory/relapsed-AML. ${ }^{25}$ We used fractionated GO $3 \mathrm{mg} / \mathrm{m}^{2}$ on days 1,4 , and 7 as in the trial ALFA-0701 ${ }^{26}$, as this schedule has been shown to be associated with a lower risk for early mortality and liver toxicity than the higher dose used in the failed SWOG S0106 trial. ${ }^{11}$ Other chemotherapies (MEC, FLAG, 
HIDAC, ...) without GO in salvage regimen for AML offer $20-60 \%$ of ORR with nearly $10 \%$ of TRM. ${ }^{27-29}$

Identification of valid and reproducible biomarkers for response to GO is necessary. Highlevel expression of CD33 was associated with a good response rate in other studies ${ }^{30}$, but our analysis did not confirm this association. Data suggest that in pediatric AML with the CC genotype on $\mathrm{CD} 33$, a substantial response to $\mathrm{GO}^{31}$ is evident, but one study on adults did not confirm this association $^{32}$.

SOS/VOD could occur during salvage and allo-HCT when patients were exposed to GO. We want to warn about $17 \%$ incidence of SOS/VOD during allo-HCT in our study despite defibrotide prophylaxis, higher than what was reported in a retrospective study of the EBMT. $^{33}$

Our multivariate results confirm the importance of the ELN prognostic classification in relapsed and refractory AML, but the study was underpowered to determine the impact of each mutation. The development of MRD detection by NGS would allow us to follow the majority of patients and increase our knowledge of response depth. ${ }^{34}$

Our study was limited by its retrospective nature and monocentric characteristics. We have also introduced a possible selection bias with the therapeutic decision of salvage therapy, consequently selecting fitter patients with fewer comorbidities.

\section{Conclusion}

In summary, we conclude that in a "real-life" setting, a GO-based intensive regimen can offer effective salvage to patients with refractory or relapsed AML, allowing achievement of response in two-thirds of the cases and a bridge to allogeneic transplant in half of them. In the future, we need to select patients according to molecular setting (NGS), biomarker of 
chemotherapy, and GO sensibility and decrease global toxicity to perform more frequently

HCT.

\section{Acknowledge}

We thank Dr Giannotti F. and Dr Ruggeri A. for their collaborative contribution in this study.

\section{Conflict of interest}

M.M has received lecture honoraria from Pfizer whose product is discussed in this article.

\section{References}

1 Cheson BD, Bennett JM, Kopecky KJ, Büchner T, Willman CL, Estey EH et al. Revised recommendations of the International Working Group for Diagnosis, Standardization of Response Criteria, Treatment Outcomes, and Reporting Standards for Therapeutic Trials in Acute Myeloid Leukemia. J Clin Oncol Off J Am Soc Clin Oncol 2003; 21: 4642-4649.

2 Slovak ML, Kopecky KJ, Cassileth PA, Harrington DH, Theil KS, Mohamed A et al. Karyotypic analysis predicts outcome of preremission and postremission therapy in adult acute myeloid leukemia: a Southwest Oncology Group/Eastern Cooperative Oncology Group Study. Blood 2000; 96: 4075-4083.

3 Thol F, Schlenk RF, Heuser M, Ganser A. How I treat refractory and early relapsed acute myeloid leukemia. Blood 2015; 126: 319-327.

4 Ramos NR, Mo CC, Karp JE, Hourigan CS. Current Approaches in the Treatment of Relapsed and Refractory Acute Myeloid Leukemia. J Clin Med 2015; 4: 665-695.

5 Wattad M, Weber D, Döhner K, Krauter J, Gaidzik VI, Paschka P et al. Impact of salvage regimens on response and overall survival in acute myeloid leukemia with induction failure. Leukemia 2017; 31: 1306-1313.

6 Potdar RR, Gupta S, Giebel S, Savani BN, Varadi G, Nagler A et al. Current Status and Perspectives of Irradiation-Based Conditioning Regimens for Patients with Acute Leukemia Undergoing Hematopoietic Stem Cell Transplantation. Clin Hematol Int 2019; 1: 19-27.

7 Craddock C, Labopin M, Pillai S, Finke J, Bunjes D, Greinix H et al. Factors predicting outcome after unrelated donor stem cell transplantation in primary refractory acute myeloid leukaemia. Leukemia 2011; 25: 808-813.

8 Brissot E, Labopin M, Stelljes M, Ehninger G, Schwerdtfeger R, Finke J et al. Comparison of matched sibling donors versus unrelated donors in allogeneic stem cell transplantation for 
primary refractory acute myeloid leukemia: a study on behalf of the Acute Leukemia Working Party of the EBMT. J Hematol OncolJ Hematol Oncol 2017; 10. doi:10.1186/s13045-017-0498-8.

9 Schlenk RF, Müller-Tidow C, Benner A, Kieser M. Relapsed/refractory acute myeloid leukemia: any progress? Curr Opin Oncol 2017; 29: 467-473.

10 Canaani J. Management of AML Beyond " $3+7$ " in 2019. Clin Hematol Int 2019; 1: 10-18.

11 Petersdorf SH, Kopecky KJ, Slovak M, Willman C, Nevill T, Brandwein J et al. A phase 3 study of gemtuzumab ozogamicin during induction and postconsolidation therapy in younger patients with acute myeloid leukemia. Blood 2013; 121: 4854-4860.

12 Hills RK, Castaigne S, Appelbaum FR, Delaunay J, Petersdorf S, Othus M et al. Addition of gemtuzumab ozogamicin to induction chemotherapy in adult patients with acute myeloid leukaemia: a meta-analysis of individual patient data from randomised controlled trials. Lancet Oncol 2014; 15: 986-996.

13 Chevallier P, Delaunay J, Turlure P, Pigneux A, Hunault M, Garand R et al. Long-term disease-free survival after gemtuzumab, intermediate-dose cytarabine, and mitoxantrone in patients with CD33(+) primary resistant or relapsed acute myeloid leukemia. J Clin Oncol Off J Am Soc Clin Oncol 2008; 26: 5192-5197.

14 Taksin A-L, Legrand O, Raffoux E, de Revel T, Thomas X, Contentin N et al. High efficacy and safety profile of fractionated doses of Mylotarg as induction therapy in patients with relapsed acute myeloblastic leukemia: a prospective study of the alfa group. Leukemia 2007; 21: 66-71.

15 Gabert J, Beillard E, van der Velden VHJ, Bi W, Grimwade D, Pallisgaard N et al. Standardization and quality control studies of 'real-time' quantitative reverse transcriptase polymerase chain reaction of fusion gene transcripts for residual disease detection in leukemia - a Europe Against Cancer program. Leukemia 2003; 17: 2318-2357.

16 Hirsch P, Zhang Y, Tang R, Joulin V, Boutroux H, Pronier E et al. Genetic hierarchy and temporal variegation in the clonal history of acute myeloid leukaemia. Nat Commun 2016; 7: 12475.

17 Döhner H, Estey E, Grimwade D, Amadori S, Appelbaum FR, Büchner T et al. Diagnosis and management of AML in adults: 2017 ELN recommendations from an international expert panel. Blood 2017; 129: 424-447.

18 Mohty M, Malard F, Abecassis M, Aerts E, Alaskar AS, Aljurf M et al. Revised diagnosis and severity criteria for sinusoidal obstruction syndrome/veno-occlusive disease in adult patients: a new classification from the European Society for Blood and Marrow Transplantation. Bone Marrow Transplant 2016; 51: 906-912.

19 Sorror ML, Maris MB, Storb R, Baron F, Sandmaier BM, Maloney DG et al. Hematopoietic cell transplantation (HCT)-specific comorbidity index: a new tool for risk assessment before allogeneic HCT. Blood 2005; 106: 2912-2919.

20 Glucksberg H, Storb R, Fefer A, Buckner CD, Neiman PE, Clift RA et al. Clinical manifestations of graft-versus-host disease in human recipients of marrow from HL-A-matched sibling donors. Transplantation 1974; 18: 295-304.

21 Filipovich AH, Weisdorf D, Pavletic S, Socie G, Wingard JR, Lee SJ et al. National Institutes of Health Consensus Development Project on Criteria for Clinical Trials in Chronic Graft-versus-Host 
Disease: I. Diagnosis and Staging Working Group Report. Biol Blood Marrow Transplant 2005; 11: 945-956.

22 Chevallier P, Roland V, Mahé B, Juge-Morineau N, Dubruille V, Guillaume T et al. Administration of mylotarg 4 days after beginning of a chemotherapy including intermediate-dose aracytin and mitoxantrone (MIDAM regimen) produces a high rate of complete hematologic remission in patients with CD33+ primary resistant or relapsed acute myeloid leukemia. Leuk Res 2005; 29: 1003-1007.

23 Paubelle E, Ducastelle-Leprêtre $\mathrm{S}$, Labussière-Wallet $\mathrm{H}$, Nicolini FE, Barraco F, Plesa A et al. Fractionated gemtuzumab ozogamicin combined with intermediate-dose cytarabine and daunorubicin as salvage therapy in very high-risk AML patients: a bridge to reduced intensity conditioning transplant? Ann Hematol 2017; 96: 363-371.

24 Chantepie SP, Reboursiere E, Mear J-B, Gac A-C, Salaun V, Benabed K et al. Gemtuzumab ozogamicin in combination with intensive chemotherapy in relapsed or refractory acute myeloid leukemia. Leuk Lymphoma 2015; 56: 2326-2330.

25 Solary E, Witz B, Caillot D, Moreau P, Desablens B, Cahn JY et al. Combination of quinine as a potential reversing agent with mitoxantrone and cytarabine for the treatment of acute leukemias: a randomized multicenter study. Blood 1996; 88: 1198-1205.

26 Castaigne S, Pautas C, Terré C, Raffoux E, Bordessoule D, Bastie J-N et al. Effect of gemtuzumab ozogamicin on survival of adult patients with de-novo acute myeloid leukaemia (ALFA-0701): a randomised, open-label, phase 3 study. The Lancet 2012; 379: 1508-1516.

27 Karanes C, Kopecky KJ, Head DR, Grever MR, Hynes HE, Kraut EH et al. A phase III comparison of high dose ARA-C (HIDAC) versus HIDAC plus mitoxantrone in the treatment of first relapsed or refractory acute myeloid leukemia: Southwest Oncology Group Study. Leuk Res 1999; 23: 787794.

28 Trifilio SM, Rademaker AW, Newman D, Coyle K, Carlson-Leuer K, Mehta J et al. Mitoxantrone and etoposide with or without intermediate dose cytarabine for the treatment of primary induction failure or relapsed acute myeloid leukemia. Leuk Res 2012; 36: 394-396.

29 Virchis A, Koh M, Rankin P, Mehta A, Potter M, Hoffbrand AV et al. Fludarabine, cytosine arabinoside, granulocyte-colony stimulating factor with or without idarubicin in the treatment of high risk acute leukaemia or myelodysplastic syndromes. Br J Haematol 2004; 124: 26-32.

30 Olombel G, Guerin E, Guy J, Perrot J-Y, Dumezy F, de Labarthe A et al. The level of blast CD33 expression positively impacts the effect of gemtuzumab ozogamicin in patients with acute myeloid leukemia. Blood 2016; 127: 2157-2160.

31 Lamba JK, Chauhan L, Shin M, Loken MR, Pollard JA, Wang Y-C et al. CD33 Splicing Polymorphism Determines Gemtuzumab Ozogamicin Response in De Novo Acute Myeloid Leukemia: Report From Randomized Phase III Children's Oncology Group Trial AAML0531. J Clin Oncol Off J Am Soc Clin Oncol 2017; 35: 2674-2682.

32 Gale RE, Popa T, Wright M, Khan N, Freeman SD, Burnett AK et al. No evidence that CD33 splicing SNP impacts the response to GO in younger adults with AML treated on UK MRC/NCRI trials. Blood 2017; : blood-2017-08-802157. 
33 Battipaglia G, Labopin M, Candoni A, Fanin R, Cheikh JE, Blaise D et al. Risk of sinusoidal obstruction syndrome in allogeneic stem cell transplantation after prior gemtuzumab ozogamicin treatment: a retrospective study from the Acute Leukemia Working Party of the EBMT. Bone Marrow Transplant 2017; 52: 592.

34 Jongen-Lavrencic M, Grob T, Hanekamp D, Kavelaars FG, al Hinai A, Zeilemaker A et al. Molecular Minimal Residual Disease in Acute Myeloid Leukemia. N Engl J Med 2018; 378: 1189-1199. 
Figures 1 and 2. Leukemia-free survival [LFS] and overall survival [OS].

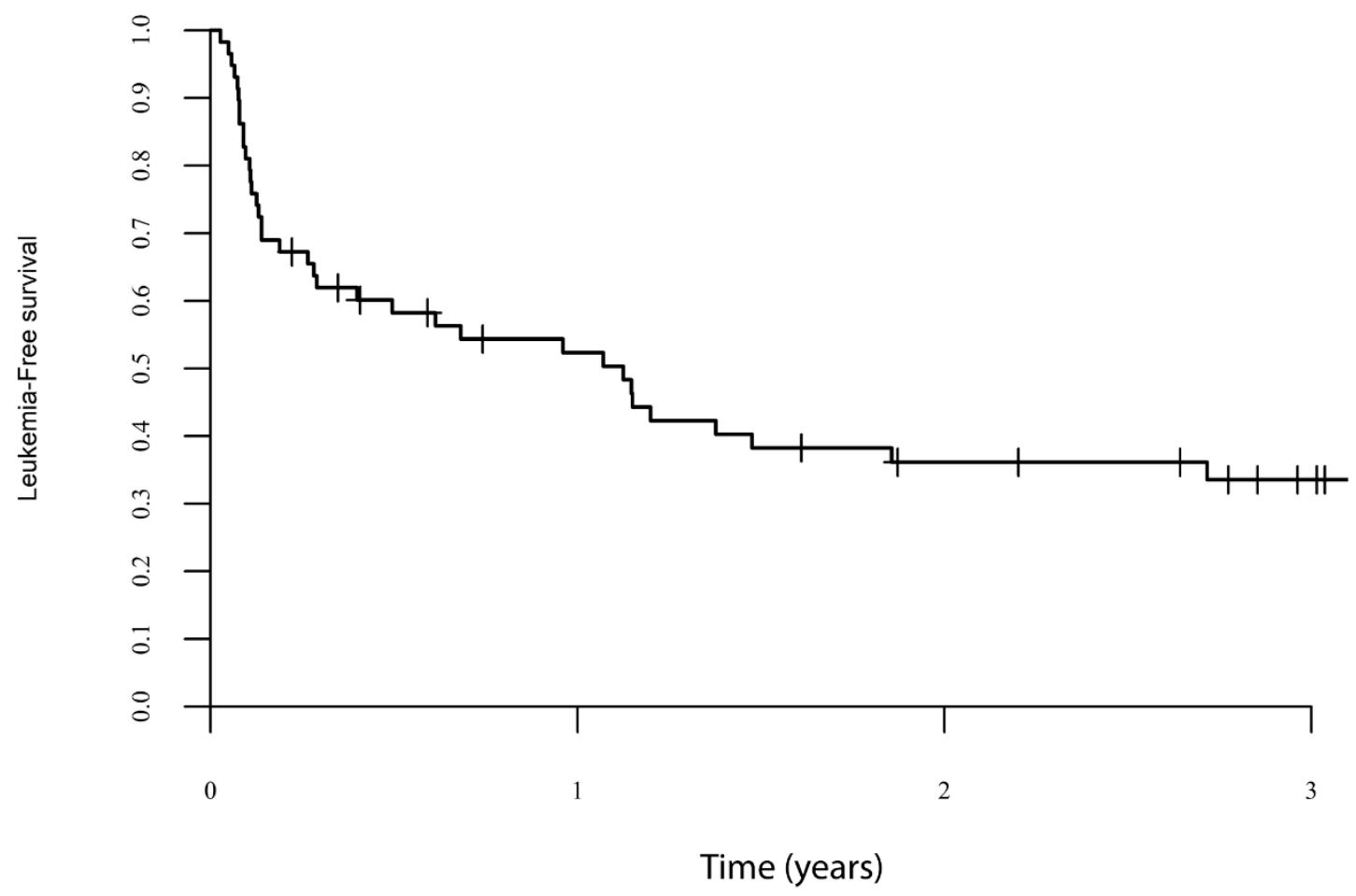

Fig 1. Leukemia-free survival curves

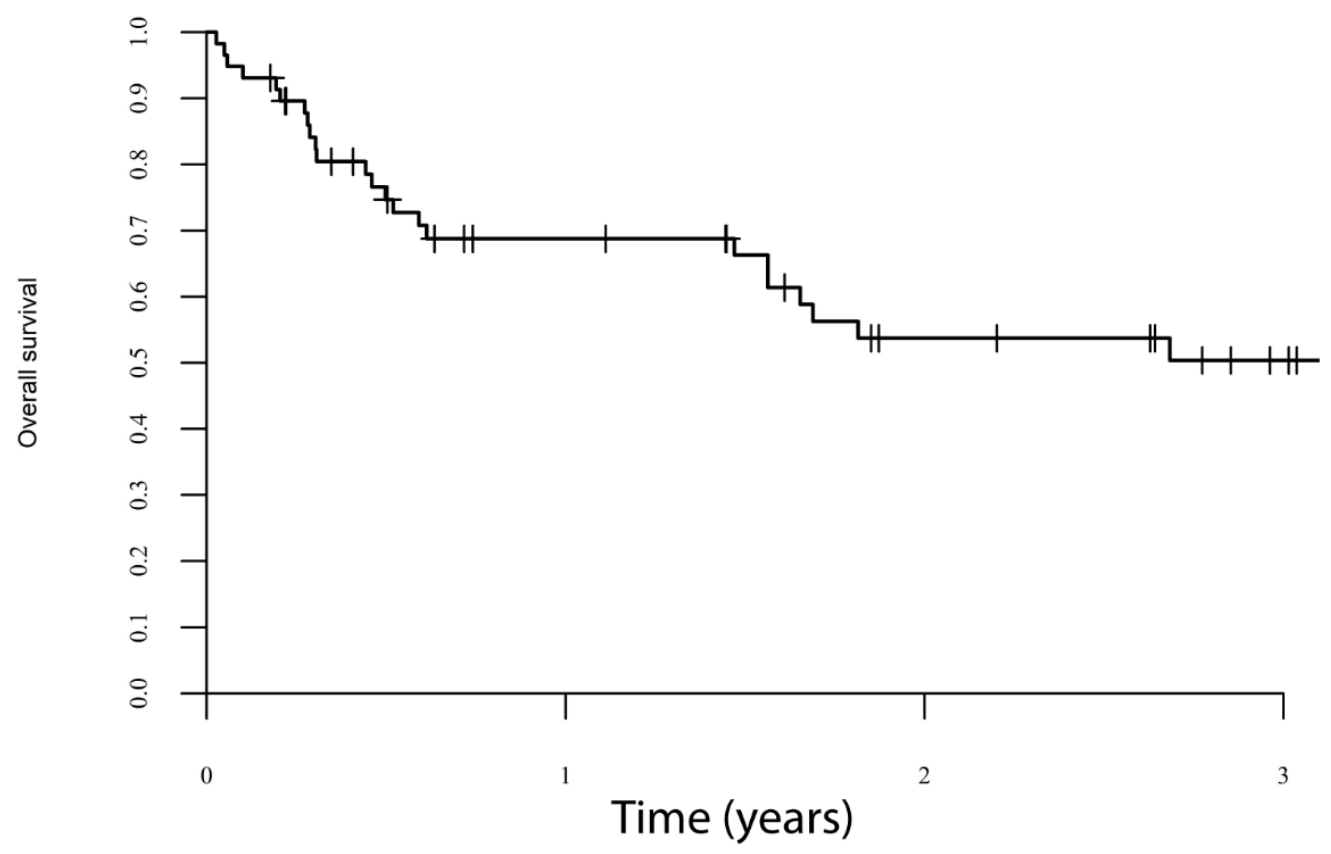

Fig 2. Overall Survival among All patients 
Figure 3. Description of patients' outcomes after MYLODAM

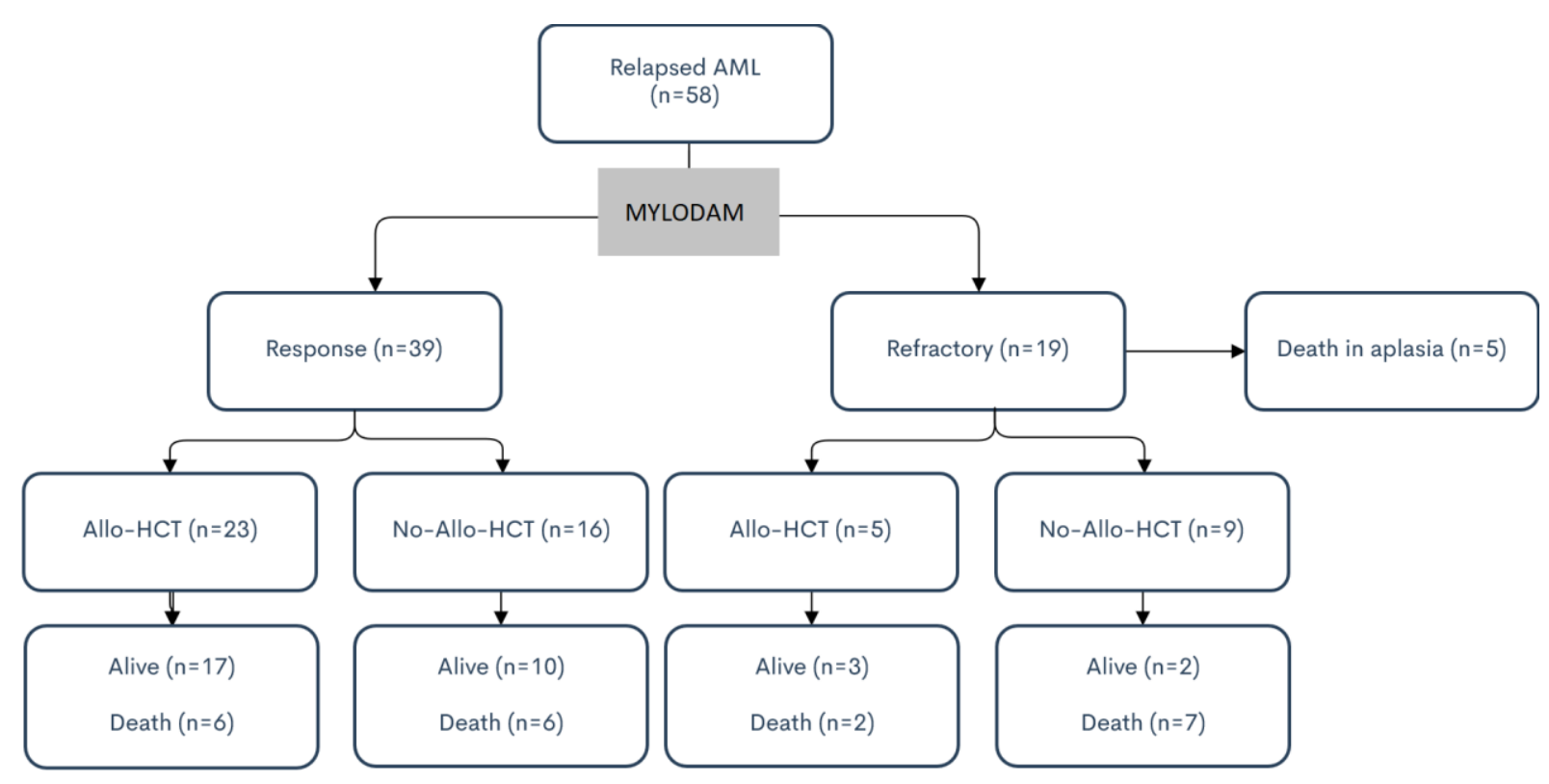


Figure 4. Description of mutation profile at diagnosis of AML.

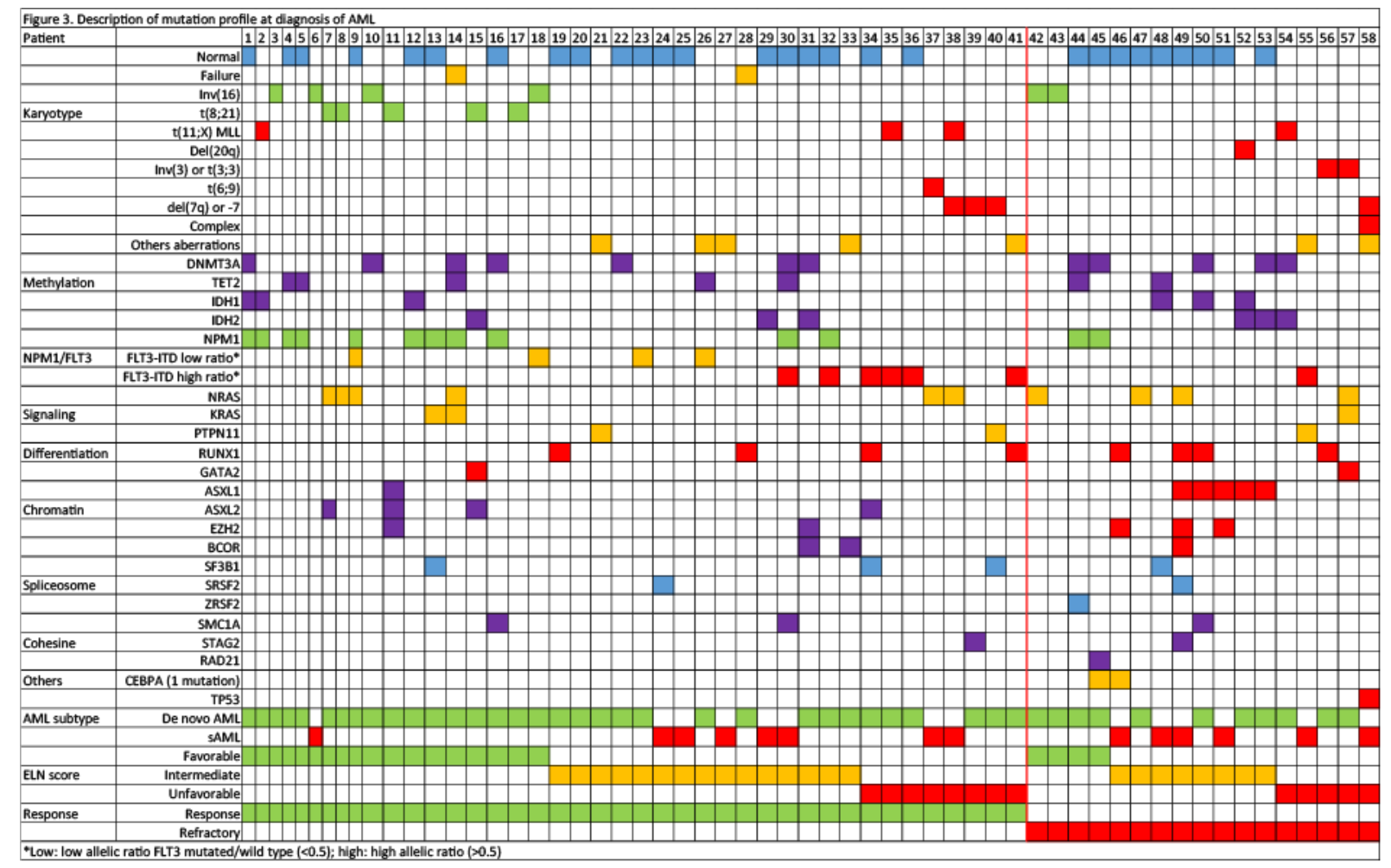


Table 1. Patient characteristics

\begin{tabular}{|c|c|}
\hline \multicolumn{2}{|l|}{ Age at salvage treatment, years } \\
\hline median (range) & $\begin{array}{c}56(16- \\
74)\end{array}$ \\
\hline$<60 \mathrm{y}$ & $33(57 \%)$ \\
\hline$\geq 60 y$ & $25(43 \%)$ \\
\hline \multicolumn{2}{|l|}{ Gender, n (\%) } \\
\hline Male & $34(59 \%)$ \\
\hline Female & $24(41 \%)$ \\
\hline \multicolumn{2}{|l|}{ Comorbidities, $\mathrm{n}$} \\
\hline HIV & 2 \\
\hline Cardiac & 3 \\
\hline Pulmonary & 2 \\
\hline Renal & 2 \\
\hline Liver & 1 \\
\hline \multicolumn{2}{|l|}{ First-line therapy, n (\%) } \\
\hline Anthracycline + Cytarabine & $46(79 \%)$ \\
\hline Anthracycline + Cytarabine + etoposide & $8(14 \%)$ \\
\hline Others & $4(7 \%)$ \\
\hline \multicolumn{2}{|l|}{ Status of disease at salvage, $\mathrm{n}(\%)$} \\
\hline Relapsed & $38(66 \%)$ \\
\hline Refractory & $20(34 \%)$ \\
\hline \multicolumn{2}{|l|}{ Lines of treatment before salvage treatment, $\mathrm{n}(\%)$} \\
\hline 1 & $41(71 \%)$ \\
\hline 2 & $7(12 \%)$ \\
\hline 3 & $9(15 \%)$ \\
\hline 4 & $1(2 \%)$ \\
\hline Prior allo-HCT & $13(22 \%)$ \\
\hline \multicolumn{2}{|l|}{ CD33 expression, $\%$} \\
\hline Median & 85 \\
\hline Range & $28-100$ \\
\hline \multicolumn{2}{|l|}{ ELN prognostic score, $\mathrm{n}(\%)$} \\
\hline Favorable & $23(40 \%)$ \\
\hline Intermediate & $21(36 \%)$ \\
\hline Adverse & $14(24 \%)$ \\
\hline
\end{tabular}


Table 2. Multivariate analysis using the Cox proportional hazards model with backward stepwise selection. Only significant univariate variables $(p<0.1)$ included.

\begin{tabular}{|c|c|c|c|c|c|}
\hline & & HR & p-value & $95 \% \mathrm{Cl}$ & \\
\hline & & & & Lower & upper \\
\hline & Refractory versus Relapse & 3 & $<0.01$ & 1.38 & 6.52 \\
\hline Response & Male versus Female & 2.8 & $<0.01$ & 1.33 & 5.93 \\
\hline & Mutations $>2$ & 1.9 & 0.05 & 0.99 & 3.73 \\
\hline & ELN favorable* & & & & \\
\hline & ELN intermediate & 1.2 & 0.71 & 0.51 & 2.67 \\
\hline LFS & ELN adverse & 2.5 & 0.04 & 1.05 & 5.79 \\
\hline & Differentiation mutations & 3.5 & $<0.01$ & 1.54 & 8.09 \\
\hline & Chromatin mutations & 2.1 & 0.06 & 0.97 & 4.56 \\
\hline & ELN favorable* & & & & \\
\hline & ELN intermediate & 0.7 & 0.54 & 0.22 & 2.18 \\
\hline OS & ELN adverse & 2.3 & 0.11 & 0.83 & 6.58 \\
\hline & Secondary leukemia & 3.2 & 0.01 & 1.30 & 7.85 \\
\hline & Chromatin mutations & 2.4 & 0.07 & 0.94 & 6.27 \\
\hline & ELN favorable* & & & & \\
\hline & ELN intermediate & 1.3 & 0.58 & 0.55 & 2.96 \\
\hline RI & ELN adverse & 2.7 & 0.02 & 1.12 & 6.38 \\
\hline & Differentiation mutations & 3.6 & $<0.01$ & 1.56 & 8.35 \\
\hline & Chromatin mutations & 2.1 & 0.06 & 0.97 & 4.67 \\
\hline
\end{tabular}

Table 3. Toxicity of MYLODAM

\begin{tabular}{|c|c|c|c|}
\hline Toxicity (WHO grade) & Grade 1-2 & Grade 3 & Grade 4 \\
\hline Infections* & 30 & 23 & 4 \\
\hline Hemorrhagic event & 4 & 4 & 5 \\
\hline Cardiac dysfunction & 2 & 0 & 1 \\
\hline Renal dysfunction & 3 & 0 & 0 \\
\hline Elevated transaminases & 30 & 9 & 6 \\
\hline GGT and alkaline phosphatase elavation & 20 & 1 & 0 \\
\hline Hyperbilirubinemia & 15 & 6 & 0 \\
\hline
\end{tabular}


Table 4. Characteristics and outcomes of allo-HCT patients

\begin{tabular}{|c|c|}
\hline & $\mathrm{N}=28$ \\
\hline Sex Ratio (M/F) & $17 / 11$ \\
\hline Median age, years (range) & $48(17-67)$ \\
\hline$>60$ years & $6(21 \%)$ \\
\hline \multicolumn{2}{|l|}{ Conditioning regimen, $\mathrm{n}(\%)$} \\
\hline MAC / RIC & $7(25 \%) / 21(75 \%)$ \\
\hline \multicolumn{2}{|l|}{ Donor Type, n (\%) } \\
\hline 10/10 MRD & $8(29 \%)$ \\
\hline 10/10 MUD & $7(25 \%)$ \\
\hline Haploidentical & $11(39 \%)$ \\
\hline CBU & $2(7 \%)$ \\
\hline \multicolumn{2}{|c|}{ Outcome 2 years after allo-HCT, \% (95\% Confidence interval) } \\
\hline LFS & $57 \%(36.3-77.5)$ \\
\hline OS & $69 \%(49.3-88.7)$ \\
\hline RI & $29 \%$ \\
\hline NRM & $16.1 \%(8.5-33.3)$ \\
\hline CI of acute GVHD II-IV at day 100 & $40 \%(15.2-64)$ \\
\hline CI of chronic GVHD & $46 \%(24.5-64.4)$ \\
\hline
\end{tabular}

Abbreviations : allo-HCT, allogeneic stem cell transplantation, M: male, F: female, MAC : myeloablative conditioning, RIC : reduced-intensity conditioning, MRD : matched related donor, MUD : matched unrelated donor, CBU : cord blood unit, LFS : leukemia-free survival, OS : overall survival, RI : relapse incidence, NRM : non relapse mortality, CI : cumulative incidence , GVHD : graft-versus-host-disease 